\title{
De Rutas Seguras a Rutas Bakanes en Chile: Co- creación con enfoque de género, educación cívica y derechos
}

\section{From Safe to Cool Routes in Chile: Co-creation with a gender, civic and rights-based focus}

\author{
Lake Sagaris, ${ }^{1}$ Maya Flores ${ }^{2}$ y Daniel Lanfranco ${ }^{3}$ \\ Fecha de recepción: 06-02-2020 - Fecha de aceptación: 29-06-2020 \\ Hábitat y Sociedad (ISSN 2173-125X), n. ${ }^{\circ}$ 13, noviembre de 2020, pp. 169-191. \\ http://dx.doi.org/10.12795/HabitatySociedad.2020.i13.10
}

\section{Summary}

An extensive literature examines the usefulness of "Safe Routes to Schools programs" to encourage active travel (walking and cycling) to school, thereby increasing physical activity with all its benefits for mental and physical health, mainly in the Global North. This article reports on an adaptation for vulnerable schools in several Chilean cities (2016-2019). This change of context transformed the program, which focused on gender, civic education, and rights as central to to a just, sustainable transport system. "Sustainable transport" is an ecology of modes that improves connections among walking, cycling and public transport. "Transport justice" becomes central in an unequal country such as Chile, focus on gender, civic education and rights. During the first experience in co-design, with students, they changed the name, rejecting "safe" and insisting on "bakan", a Chilean term for "cool". The results included changes in attitudes, skills and visions. The resulting program, Kool Routes, improves physical activity, but above all influences the social determinants of health. It has proven to be a relatively simple way of dealing with the complexity of the challenges inherent in achieving sustainable development goals for cities in the 21st century.

\section{Key words}

Safe routes; Education; Sustainable transport; Active transport; Rights; Children

\begin{abstract}
Resumen
Una literatura internacional examina la utilidad de programas denominados "Safe Routes to School" o Rutas Seguras a las Escuelas, para fomentar el transporte activo (principalmente la caminata y la bicicleta) y con ello niveles de actividad física suficientes para mejorar la salud física y mental, casi exclusivamente en el hemisferio norte. Este artículo presenta una adaptación de estos programas en escuelas vulnerables de varias ciudades chilenas (2016-2019), utilizando una estrategia de investigación participativa para la acción. Definimos al "transporte sustentable" como una ecología de modos que mejora las interconexiones entre la caminata, la bicicleta y el transporte público. En países tan desiguales como Chile, el transporte "justo" conecta la sustentabilidad con la acción comunitaria. Al integrar un enfoque de género, educación cívica y derechos, el programa cambió, incluso de nombre, ya que las niñas y niños querían rutas "bakanes", o sea, "geniales". Cocreamos el programa con sus estudiantes, profesores y, eventualmente y las autoridades de planificación local. El resultado fue cambios profundos en las actitudes, capacidades y visiones. Rutas Bakanes mejora la actividad física, pero por sobre todo actúa sobre los determinantes sociales definidos por la Organización Mundial de la Salud, abordando la complejidad de los objetivos de desarrollo sustentable.
\end{abstract}

\section{Palabras clave}

Rutas seguras; Educación; Transporte sustentable; Transporte activo; Enfoque de derechos; Niñ@s; Investigación participativa para la acción

\footnotetext{
1 Profesora asociada adjunta del Departamento de Ingeniería de Transporte y Logística. Pontificia Universidad Católica de Chile, 4860 Vicuña Mackenna, Santiago, Chile. E-mail: lsagaris@uc.cl ORCID: 0000-0002-9162-5190.

2 Licenciada en Actividad Física y Deportes, Laboratorio de Cambio Social. E-mail: mayaflores@gmail.com.

3 Antropólogo, Laboratorio de Cambio Social. E-mail: dslanfranco@gmail.com.
} 
El movimiento "Ciudades Saludables" ${ }^{4}$ ha sido un proceso de casi 30 años, y entendemos cada vez más las particularidades de cómo convertir a una ciudad en saludable. Lo que aún no entendemos muy bien, sin embargo, es cómo potenciar los beneficios de la salud y asegurarnos que lleguen a la ciudadanía de zonas urbanas del mundo entero (Rydin et al. 2012, traducción propia).

\section{Introducción: Cicloinclusión en América Latina, la bicicleta como instrumento de cambio social}

Entendemos el urbanismo como una disciplina primordialmente práctica, sin excluir componentes técnico-artísticos, que conversa con un corpus teórico en constante proceso de cambio. Partió como una búsqueda de una explicación analítica y sintética de la forma urbana, principalmente de la ciudad como una manifestación histórica (Almandoz, 2013), pero desde entonces y a raíz del desarrollo de la planificación, como actividad práctica y disciplina académica, las miradas integran cada vez más los temas humanos, sociales y culturales (Faludi, 1978).

Si en siglos anteriores el objetivo de la planificación urbana-regional era ordenar actividades para minimizar sus efectos negativos, particularmente en la salud humana, por la contaminación de las actividades productivas, desde el siglo xx en adelante surgen demandas de equidad e inclusión social como centrales (Sandercock, 1998; Fainstein, 2010; Friedmann, 2011). Y para el siglo xxI, naciente, surgen conflictos sociales y desafíos asociados al medio ambiente y la imposibilidad de seguir soportando la explotación intensiva de siglos anteriores.

Así surgen los Objetivos de Desarrollo Sustentable (ONU, 2015) y una nueva Agenda Urbana (UNHabitat, 2016) como metas centrales, donde se juega el futuro de la humanidad y, posiblemente, la vida en la Tierra. Un lazo directo y potente entre estos desafíos y el ámbito humano es la salud: en cada cuerpo los déficits, tóxicos y beneficios del medio ambiente toman cuerpo literalmente, mientras en cada comunidad, ciudad y país, esta conexión a la vez íntima y pública refleja e impacta en las políticas y presupuestos de cada escala de gobierno local, regional y nacional.

En este sentido, es particularmente potente la relación entre el sistema de transporte, el medio ambiente y la salud, la que se ha convertido en objeto de considerable interés en años recientes (Mindell, Watkins y Cohen, 2011; Rydin, 2012; Boniface, Scantlebury, Watkins y Mindell, 2015; Mindell, 2017). Asociado a esto, y por sus impactos en la contaminación del agua, del aire y por ruido, surge el tema de la morfología urbana, afectada por el crecimiento desmedido del automóvil como primera prioridad para la movilidad. Pasa a ser un verdadero motor de expansión, extendiendo los bordes y creando ciudades de baja densidad, flujos rápidos, nudos y congestión, y niveles de inseguridad vial como nunca vistos.

Este modelo de desarrollo urbano encierra desafíos mayores para la salud, por las colisiones y contaminantes, pero también por la pérdida de espacios para socializar, recrearse, y para ejercer los derechos humanos y cívicos asociados a la calle como espacio de encuentro, conflicto, debate y movimientos, no solo de vehículos, sino de colectivos sociales que interrogan, critican y proponen innovaciones en las estructuras sociales. 
Entra en conflicto con esta mirada multipropósito de las calles la "automovilidad" que, desde los setenta, pasa a ser un fenómeno internacional, quizás el rostro más ubicuo de la globalización, constituyendo un fenómeno urbano y económico, que constituye una verdadera ideología asociada a la libertad y el progreso individual, en un marco profundamente neoliberal (Sheller y Urry, 2000; Beckmann, 2001; Urry, 2004). Como observan estos estudiosos, junto con el fenómeno del poder y el dominio del automóvil, surge una reacción que se contrapone, que se expresa, por ejemplo, en los movimientos holandeses en pro de la seguridad vial, las niñas y niños y la bicicleta.

Así, en algunos países más y en otros menos, pero prácticamente desde los inicios de la automovilidad, vemos cómo diversos movimientos sociales contraponen la movilidad en bicicleta (Replogle, 1992; Cavill, 2003; Root, 2003; Tolley, 2003; Shanbaug, 2012). Esto ocurre especialmente en ciudades que aspiran a una vida digna, espacios públicos patrimoniales y hermosos, con abundante vegetación y una seguridad "natural" que surge del uso intenso por públicos diversos de las plazas, paraderos, estaciones de trenes y otros espacios vitales (Gehl, 2011).

Por lo mismo, desde 1990, comienza a construirse una ciencia de un urbanismo "cicloinclusivo", término holandés, que se refiere a la plena integración de las bicicletas, triciclos y accesorios en la planificación urbana. A principios de 2000, estas ideas llegaron a América Latina, en manos de una organización no gubernamental, Interface for Cycling Expertise (I-CE), agrupación que durante una década realizaba visitas técnicas a Santiago, Quito, Bogotá, Río de Janeiro, entre otras, capacitando a líderes de organizaciones de la sociedad civil y planificadores urbanos, inquietos y buscadores de cómo hacer ciudades más humanas (Sagaris, 2019).

En Latinoamérica el término cicloinclusivo fue adquiriendo más significados: puesto que la bicicleta era percibida como vehículo de pobres y recicladores, lo de "inclusivo" incorporó también matices asociados a la justicia, la equidad y la inclusión social. Este significado se consolidó en años más recientes, con la convicción de organizaciones pro-bici que más que pelear solo por la bicicleta, es importante integrar la caminata, la bicicleta y el acceso universal para personas con discapacidades relacionadas con la movilidad.

Surgen los primeros cuestionamientos de temas de género y bicicleta con trabajos desde Australia, de Jan Garrard (2003), quien observa que la participación de la mujer en el uso de este modo es un indicador real de la calidad de la cicloinclusión de la ciudad. Donde más baja la participación de mujeres, más malas suelen ser las ciclofacilidades, situación que contrasta con los Países Bajos, donde las mujeres son un poco más de la mitad de los usuarios de este modo (Pucher y Buehler, 2008).

Con estudios más recientes, empieza a surgir la relevancia de la cicloinclusión desde una perspectiva de género, en América Latina, primero por el uso de la bicicleta, que es menor entre mujeres, pero más necesario por temas de salud y participación social (Díaz y Rojas, 2017). Por sobre todo, a raíz de estudios de género, seguridad y transporte público emergen posibilidades importantes para la bicicleta, la bici-taxi, la bici-carga y otras modalidades de simplificar la vida de mujeres, incluso no ciclistas (Sagaris y Arora, 2016; 2018), al proporcionar un modo económicos para viajes de "cuidado" (Sánchez de Madariaga y Zucchini, 2019). Estas miradas desde distintos rincones del norte y el sur del mundo son potenciados por el trabajo de urbanismo feminista surgido en España (Col-lectiu Punt 6, 2019), entre otros. 
Reconocen que para las mujeres, moverse por la ciudad es un tema complejo. Como ocurre con el trabajo dentro y fuera del hogar, en sus viajes cotidianos las mujeres viven una doble carga, en este caso de violencia, al temer ser víctima de la violencia delictual, pero también al sentirse constantemente acosadas y afectadas por situaciones de violencia de género (Allen, Pereyra, Sagaris y Cárdenas, 2019). En estos contextos, contar con la ayuda de un circuito de bici-taxis entre un paradero rural y un hospital regional, por ejemplo, o tener acceso a bicicletas públicas con sillas para infantes, a bici-cargas (propias, prestadas u operadas como servicio) puede simplificar significativamente las tareas de las mujeres, permitiendo un mayor acceso a la ciudad, y por lo tanto un ejercicio más pleno de sus derechos. Similarmente, una mirada de género, aplicada transversalmente como parte del programa descrito en este artículo, cambió significativamente la participación de niñas y niños, y sus actitudes frente a estos temas.

\section{Bicicletas + viajes a la escuela: un puente práctico a la salud}

Es en este contexto que la bicicleta no solo como instrumento de movilidad personal, sino como vehículo de cambio social, comienza a tomar fuerza en diversos ámbitos, particularmente la salud. Sus efectos positivos en la salud son ampliamente demostrados, superando a los riesgos por magnitudes mayores (Teschke, Reynolds, Ries, Gouge y Winters, 2012; Tainio et al., 2016; Rojas-Rueda, de Nazelle, Tainio y Nieuwenhuijsen, 2011). Al nivel urbano está comprobado para diversos países, contextos y condiciones que, mientras mayor la cantidad de gente que camina y pedalea, menores son los índices de morbilidad y mortalidad por siniestros viales (Jacobsen, 2003; Pucher y Buehler, 2007; Jacobsen, Ragland y Komanoff, 2015; Elvik y Bjørnskau, 2017).

Junto con la evidencia de sus beneficios para la salud, surge la valoración de la caminata y el pedaleo como movilidad entre el hogar y la escuela, en el momento justo cuando niñas y niños dejan de utilizar estos modos en los países desarrollados, generadores de estos mismos estudios. Efectivamente, desde 1990 vemos una creciente preocupación por el poco espacio que les va quedando para jugar y movilizarse caminado o pedaleando hacia la escuela (Hillman, Adams y Whitelegg, 1990). Frente a esta situación, desde los setenta, aparecen los primeros programas de Rutas Seguras, en Dinamarca, y luego el Reino Unido, Australia, Canadá y Estados Unidos.

Más recientemente, estos pilotos derivaron en redes y programas nacionales, manuales y políticas públicas, que definen a Rutas Seguras como programas que "hacen seguro, conveniente, y entretenido caminar y pedalear para niños y niñas hacia y desde la escuela. Su objetivo es lograr que más niños y niñas caminen y pedaleen a la escuela, para mejorar su seguridad, y mejorar su salud y actividad física" (SafeRoutesUS, 2018). Pueden ser implementados a nivel ciudad, distrito o simplemente a nivel de escuela, con muchos insumos ya generados por otros programas, disponibles en internet. De hecho una búsqueda en Google de "Safe Routes to School" identificó casi un millón de resultados en inglés, apenas 16900 en español (5 de febrero 2020).

Los países en desarrollo también sufren del dominio de los automóviles, siendo los atropellos la mayor causa de muerte infantil (UNEP/ FIA, 2016). Las condiciones de inseguridad, violencia de género y po- 
breza limitan severamente la movilidad de personas vulnerables, particularmente niños y niñas, mujeres y personas mayores o en situación de discapacidad.

Con el $90 \%$ de la población ya viviendo en ciudades, Chile ofrece una oportunidad excelente para estudiar estos temas. Tanto personas adultas como niños y niñas tienen altos índices de sedentarismo (90\%) y los índices de obesidad y sobrepeso están entre los más altos del mundo. Esto nos hace preguntar sobre el potencial impacto que programas enfocados en el transporte activo tendrían para la población.

Nuestra investigación buscó explorar el potencial de una adaptación chilena de programas de Rutas Seguras en la actividad física entre niños y niñas de un barrio vulnerable en El Bosque, una comuna (jurisdicción municipal) del área metropolitana de Santiago. ¿Era factible un programa de esta naturaleza? ¿Qué cambios serían necesarios para adaptarlo a una realidad muy distinta, en un país latinoamericano con grandes desigualdades entre distintos grupos de la población? ¿Cómo superar la inseguridad — vial, delincuencial, de género- en espacios urbanos marcados por múltiples y complejas formas de violencia?

Los resultados nos llevaron más allá de estas preguntas de partida, sin embargo, revelando que, con cambios para responder a esta nueva realidad, estos programas demuestran una potencialidad transformadora en múltiples esferas, particularmente de género, seguridad social y lo urbano, relacionadas con estrategias más integrales, como calles para todas y todos, calmado de tráfico, educación cívica y ambiental.

En el apartado siguiente resumimos los métodos utilizados, en el marco de una investigación participativa para la acción. En esta metodología, distinguimos entre los resultados, o sea, lo realizado, en este caso en tres zonas urbanas muy distintas (apartado 3) y los aprendizajes en cuanto a la agenda mundial pro-salud, liderada por la OMS, y los Objetivos de Desarrollo Sustentables de la ONU (apartado 4), antes de terminar con una reflexión final sobre las implicancias para las ciudades y futuras investigaciones (apartado 5).

\section{Metodología: Investigación para la Acción: Co-creando un programa para Chile}

La investigación participativa para la acción (IPA) busca transformar las tradicionales relaciones entre investigadores e investigados, generando un proceso democrático y participativo cuyo fin es generar conocimientos prácticos para mejorar la vida humana (Reason y Bradbury, 2006).

La pedagogía se basa en la ética de Paulo Freire (1998), particularmente su pedagogía de la liberación/autonomía, que crea relaciones más horizontales entre profesor y estudiante, reconociendo que de abrirse a las múltiples posibilidades y fuerzas de cada participanteaprendiz, existe la oportunidad de generar aprendizajes mutuos, donde diversas personas, tanto la que ocupa el rol de profesor o instructora como la que es estudiante, tienen expertise y vacíos en su expertise, que se pueden ir llenando a través de un intercambio.

Para este trabajo, aplicamos una variante de la "ciencia de la acción" (action science), desarrollada originalmente por Argyris y Schön (1974). Desde esta perspectiva, un "científico de la acción" realiza una "intervención", que busca probar y promover un nuevo sistema de aprendizaje dentro de una comunidad (cfr. Argyris y Schon, 1974, p. 131; Friedman, 2008). 
Formamos un equipo pequeño de una profesora de educación física y un antropólogo, ambos expertos en el uso, la mantención y la promoción de la bicicleta como modo de transporte urbano, y ambos con experiencia en temas de género y bicicleta (Escuela BiciMujer, Santiago, 2010-2019), nuevas masculinidades y activismo pro-bici.

El equipo formaba parte del Laboratorio de Cambio Social (el Lab), una instancia de investigación-acción creada por Ciudad Viva, organización de urbanismo ciudadano, en colaboración con tres centros de investigación de la Pontificia Universidad Católica de Chile (PUC): el Departamento de Ingeniería y Logística de Transporte, el Centro de Desarrollo Urbano Sustentable (CEDEUS) y el Centro de Excelencia en transporte rápido en buses, Centro BRT+. El Lab aportaba conocimientos de urbanismo, ingeniería, transporte y planificación/geografía, más una amplia red de contactos con organizaciones ciudadanas y planificadores locales/regionales, fruto de más de 20 años de colaboraciones, muchas relacionadas con transporte y la cicloinclusión.

Aplicando los principios de la "ciencia en acción" (Friedman, 2008), partimos en noviembre 2016 con actividades exploratorias en dos escuelas de El Bosque. Más que simplemente enseñarles a niños y niñas a pedalear o diseñar rutas para estos propósitos, el desafío era potenciar un pensamiento crítico entre niños y niñas, ${ }^{5}$ utilizando un marco conceptual desarrollado en otras investigaciones. Según estos trabajos, frente a la automovilidad y una movilidad insustentable, definimos el "transporte sustentable" como una ecología de modos, que puede potenciarse al enfocar y mejorar la intermodalidad caminata-bici-bus, involucrando a sus respectivos usuarios, de diversas características (Sagaris y Arora, 2016; Sagaris, Tiznado-Aitken y Steiniger, 2017; Sagaris y Lanfranco, 2019; Sagaris y Tiznado-Aitken, 2020).

No queríamos presuponer nada, así que cada fase comenzó con meses de exploración a través de talleres participativos, donde co-construimos estas ideas en conjunto con la comunidad escolar, principalmente niños y niñas, hasta definir las actividades claves para seguir con las siguientes fases del programa.

Fue en esta primera etapa que los participantes insistieron en cambiarle el nombre del programa, dejando atrás Rutas Seguras y quedando con Rutas Bakanes, lo que significó abordar mucho más que la seguridad, tomando temas relacionados con la participación y la felicidad. Como veremos, más abajo, en la última versión de este experimento, en Lautaro, tuvimos que integrar el "urbanismo ciudadano", o sea, la ciudadanía como planificadores y protagonistas de la toma de decisiones claves sobre su medio.

\section{Sobrepeso, obesidad y salud en Chile}

En Chile, el sedentarismo, la obesidad y sus costos relacionados son barreras importantes a lograr una salud de calidad, lo cual ha sido uno de sus objetivos principales desde el término de la dictadura militar (1973-1990). Entre países OCDE, Chile se encuentra en octavo lugar para obesidad entre adultos, segundo en Latinoamérica (OCDE, 2017). Para niños y niñas, Chile se encuentra en el segundo lugar después de México, tanto para sedentarismo como para obesidad (Aguilar-Farias, Martino-Fuentealba et al., 2018).

La obesidad y sus enfermedades asociadas han ido incrementando desde los años sesenta, con la obesidad alcanzando un 38,4\% entre mujeres y un 30,3\% entre hombres (en 2017), muy similar a los Esta- 
dos Unidos, el país con peor índice en el mundo (cfr. Mardones et al., 2018, p. 23). Mientras la desnutrición ha bajado, el 34,6\% de los niños y niñas bajo los seis años de edad sufren de sobrepeso u obesidad. Similarmente, al comenzar la escuela después de los seis años, niños y niñas tienen un índice cercano al 25\%. Para la población en general, el sobrepeso y la obesidad afectan al $70 \%$ de la población, siendo la obesidad más común entre mujeres, en áreas rurales y en sectores de bajos o medianos ingresos (cfr. Mardones et al., 2018, p. 28).

En la infancia, el sobrepeso y la obesidad están relacionados con baja autoestima, depresión y exclusión social, mientras la obesidad infantil está relacionada con alta probabilidad de mortalidad cardiovascular más tarde en la vida. El sobrepeso también está relacionado con altos índices de inasistencia a la escuela, en el caso de niños y niñas, y con el trabajo, para personas adultas. De hecho, un estudio reciente informa que esta situación le cuesta al país un 0,54\% de su PIB con una proyección de llegar al 1,46\% en 2030 (cfr. Centro Avanzado de Enfermedades Crónicas, 2017, citado en Mardones et al., p. 31). Trabajadores con obesidad tienden a tener un $25 \%$ más de inasistencias al trabajo y sus costos de salud son un $58 \%$ más altos que aquellas personas con un índice de masa corporal normal (Zárate et al., 2009, citado en Margozzini y Bambs, 2018, p. 354).

Sin embargo, la mayor parte de las políticas públicas enfocan la malnutrición etiquetando los alimentos con alto contenido de sodio, grasa o azúcares, pero siendo muy deficientes en promover la actividad física. Solo el $20 \%$ de la juventud (entre los 9 y 18 años) logra incorporar la actividad física dentro de sus rutinas diarias, dándonos el índice más bajo en Latinoamérica después de Venezuela.

En respuesta a esto, investigadores chilenos recomiendan educación prenatal; amamantamiento y desarrollo temprano en niños y niñas; regulación de alimentos insalubres; medidas para reducir diferencias socioeconómicas en cuanto acceso a comida sana; y promoción de la actividad física. Chile ha avanzado notoriamente en amamantamiento, mientras que los programas a nivel escolar han probado ser deficientes para reducir la malnutrición y aumentar la actividad física (cfr. Margozzini y Bambs, 2018, pp. 354-359).

La inactividad física refleja la marcada desigualdad social. Mientras que niños y niñas en barrios adinerados tienen acceso a $18,8 \mathrm{~m}^{2} /$ por persona de espacios verdes, comunidades de bajos ingresos tienen acceso a $0,4-2,9 \mathrm{~m}^{2} /$ por persona de espacios verdes (cfr. Aguilar-Farias y Cortinez-O'Ryan, 2018, p. 452). Inversión en deportes va en su gran mayoría a deportes competitivos (53\%), con un mero $5 \%$ yendo a programas que potencian la actividad física dentro de la vida diaria. Mientras el $79 \%$ de las personas que viven en barrios de altos ingresos los consideran seguros para sus niños y niñas, solo el $40 \%$ de las personas en barrios de bajos ingresos tienen esta misma percepción sobre sus propios barrios (cfr. ob. cit., pp. 452-453).

\section{Un enfoque de sustentabilidad, equidad y género como derechos propios}

A la estrategia IPA general, ya descrita, agregamos un enfoque basado en los derechos humanos, ya que esto se recomienda en el caso de trabajar con grupos de población objetos de una mayor marginación, exclusión y discriminación, buscando reequilibrar los beneficios de pertenecer a una sociedad o una comunidad, redistribuyendo el po- 
der, la agencia, los sacrificios y los beneficios justamente entre grupos sociales muy diversos.

Este enfoque requiere un análisis de las normas de género, de las diferentes formas de discriminación y de los desequilibrios de poder, a fin de garantizar que las intervenciones lleguen a los segmentos más marginados de la población. Es un instrumento que usa el discurso de la teoría constitucional e internacional de los derechos humanos, pero que a su vez incorpora una dimensión política, ya que pasa a ser central la toma de decisiones que afectan el bienestar común y particular de cada grupo constituyente de la sociedad. Quiénes toman las decisiones, a quiénes deben escuchar y cómo deben pesar las opiniones de los diversos grupos con interés en cada tema es central para constituir vías relativamente pacíficas, capaces de canalizar conflictos y desacuerdos y llevarlos a cambios que gozan de un apoyo basado en amplios consensos (PA-CIPD, 1994).

\begin{tabular}{|c|c|c|}
\hline & Enfoque de Derechos & Aplicación Rutas Bakanes \\
\hline 1 & $\begin{array}{l}\text { Un objetivo central del desarrollo es el pleno ejerci- } \\
\text { cio de los derechos de cada sujeto, siendo las mismas } \\
\text { personas los agentes principales de su propio desarro- } \\
\text { llo, en lugar de receptores pasivos de productos y ser- } \\
\text { vicios. }\end{array}$ & $\begin{array}{l}\text { La comunidad escolar, particularmente los estudian- } \\
\text { tes y profesores juegan un papel central en el co-dise- } \\
\text { no del programa. }\end{array}$ \\
\hline 2 & $\begin{array}{l}\text { La participación es a la vez un medio y un objetivo, } \\
\text { siendo central estrategias de empoderamiento a través } \\
\text { de alianzas relevantes, particularmente a los grupos } \\
\text { menos poderosos, y el Estado el principal garante de } \\
\text { derechos y el papel de otros agentes no estatales. }\end{array}$ & $\begin{array}{l}\text { Realizamos el programa en comunas vulnerables y } \\
\text { mixtas, en la región metropolitana de Santiago y en } \\
\text { ciudades de provincia con características muy diver- } \\
\text { sas. }\end{array}$ \\
\hline 3 & $\begin{array}{l}\text { El desarrollo local es primordial, y la acción se basa en } \\
\text { un análisis de causas inmediatas, subyacentes y funda- } \\
\text { mentales. }\end{array}$ & $\begin{array}{l}\text { El principal socio fuera de la escuela es el gobierno } \\
\text { local, a veces con alguna participación del gobierno } \\
\text { regional. }\end{array}$ \\
\hline 4 & $\begin{array}{l}\text { Tanto los resultados como los procesos son supervisa- } \\
\text { dos y evaluados. }\end{array}$ & $\begin{array}{l}\text { Mantenemos bitácoras, datos de asistencia y otros re- } \\
\text { gistros que son monitoreados en reuniones semanales } \\
\text { y evaluados anualmente. }\end{array}$ \\
\hline 5 & $\begin{array}{l}\text { Las normas de los derechos humanos dirigen la for- } \\
\text { mulación de objetivos, metas e indicadores medibles } \\
\text { en la programación. }\end{array}$ & $\begin{array}{l}\text { Utilizamos sistemas de educación basados en el idea- } \\
\text { rio de Paulo Freire y otros, y métodos de facilitación y } \\
\text { conversación horizontal y con formalidades mínimas. }\end{array}$ \\
\hline 6 & $\begin{array}{l}\text { Los sistemas nacionales de rendición de cuentas de- } \\
\text { ben ser reforzados con el objetivo de garantizar una } \\
\text { revisión independiente del desempeño del gobierno } \\
\text { así como el acceso a vías de recursos para los sujetos } \\
\text { agraviados. }\end{array}$ & $\begin{array}{l}\text { Buscamos desarrollar RB como programa nacional } \\
\text { presente en todas las escuelas, partiendo con su inte- } \\
\text { gración en un informe Balance de Transporte Justo } \\
(2020) \text {. }\end{array}$ \\
\hline
\end{tabular}

Cuadro 1. Aplicación del enfoque de derechos en Rutas Bakanes, Chile (20162019). Fuente: Elaboración propia, en base a los Atributos del enfoque de derechos (Oficina del Alto comisionado de las Naciones Unidas para los Derechos Humanos, 2006) y los Elementos de las buenas practicas propios del enfoque basado en derechos, del Programa de Acción de la Conferencia Internacional sobre la Población y el Desarrollo (PACIPD).
Una meta central es lograr la igualdad y la dignidad de todas las personas, siendo elementos centrales de las buenas prácticas una serie de elementos relacionados con la participación, la colaboración y el empoderamiento. Aplicamos la mayoría de estos principios en estos programas Rutas Bakanes (Cuadro 1), como parte integral de cada intervención. 


\section{Actividades y resultados en las escuelas y sus entornos}

\section{Fases, lugares y colaboradores}

Dadas las oportunidades para promover la equidad, argumentadas en los apartados anteriores comenzamos a desarrollar un programa en un barrio de bajos ingresos con fuertes vínculos entre el gobierno local y las organizaciones comunitarias. Ubicada en la periferia de la Región Metropolitana de Santiago, la comuna de El Bosque tiene una partición modal muy alta para la caminata $(52 \%$ versus el promedio de la ciudad $34 \%$ ), menor en términos de ciclismo (3\% versus $4 \%$ para el resto de la ciudad), y uso del sistema de transporte público menor a lo esperado ( $14 \%$ versus el $25 \%$ del resto de la ciudad).

El Bosque se convirtió en el foco de la fase 1, donde exploramos, desarrollamos y testeamos un programa escolar que integraría todas las edades desde los 4 hasta los 13 años (2017). Las actividades estuvieron recluidas principalmente dentro de esta escuela y comuna durante el 2017 y en el 2018 expandimos el programa a diferentes contextos, especialmente a las comunas de Independencia y Lautaro (Cuadro 2).

\begin{tabular}{|c|c|c|c|c|c|c|}
\hline \multirow{2}{*}{$\begin{array}{l}\text { Fecha } \\
\text { Inicio }\end{array}$} & \multirow{2}{*}{ Ubicación } & \multirow[t]{2}{*}{ Características } & \multirow{2}{*}{$\begin{array}{l}\text { Población } \\
\text { Censo } 2017\end{array}$} & \multirow{2}{*}{$\begin{array}{l}\text { Índice de } \\
\text { Pobreza }\end{array}$} & \multicolumn{2}{|c|}{ Partición Modal } \\
\hline & & & & & $\begin{array}{l}\text { Caminata }+ \\
\text { Bicicleta }+ \text { Bus }\end{array}$ & $\begin{array}{l}\text { Auto- } \\
\text { móvil }\end{array}$ \\
\hline 2016 & $\begin{array}{l}\text { El Bosque, San- } \\
\text { tiago. }\end{array}$ & $\begin{array}{l}\text { Jurisdicción de la región } \\
\text { metropolitana ubicada } \\
\text { en la periferia con altos } \\
\text { índices de desigualdad y } \\
\text { vulnerabilidad. }\end{array}$ & $\begin{array}{l}162505 \text { total; } \\
33,017 \text { bajo los } \\
15 \text { años de edad. }\end{array}$ & $\begin{array}{l}14.5 \% \text { (casi el } \\
\text { triple del pro- } \\
\text { medio de la } \\
\text { ciudad). }\end{array}$ & $\begin{array}{l}52 \%+3 \%+ \\
14 \%\end{array}$ & $17 \%$ \\
\hline 2018 & $\begin{array}{l}\text { Lautaro, } 9^{\text {th }} \text { Re- } \\
\text { gion de la Arau- } \\
\text { canía. }\end{array}$ & $\begin{array}{l}\text { Pequeña ciudad rural } \\
\text { con alto porcentaje de } \\
\text { población indígena. }\end{array}$ & $\begin{array}{l}38000 \text { total; } \\
8440 \text { bajo los } 15 \\
\text { años de edad. }\end{array}$ & $\begin{array}{l}30 \%, 10 \% \text { so- } \\
\text { bre el prome- } \\
\text { dio regional. }\end{array}$ & $\mathrm{N} / \mathrm{A}$ & $\mathrm{N} / \mathrm{A}$ \\
\hline 2018 & $\begin{array}{l}\text { Independencia, } \\
\text { Metro Santiago. }\end{array}$ & $\begin{array}{l}\text { Jurisdicción municipal } \\
\text { de la Región metropo- } \\
\text { litana, con ingresos me- } \\
\text { dios y bajos, cerca del } \\
\text { centro de Santiago. }\end{array}$ & $\begin{array}{l}100281 \text { total; } \\
16834 \text { bajo los } \\
15 \text { años de edad. }\end{array}$ & $\begin{array}{l}10 \%(2015 \\
\text { data). }\end{array}$ & $\begin{array}{l}40 \%+4 \%+ \\
23 \%\end{array}$ & $25 \%$ \\
\hline
\end{tabular}

Mientras progresaba el programa desarrollamos la fase 2, de Intervenciones urbanas alrededor de las escuelas, lo cual requería una mayor planificación urbana y un componente de diseño importante. Esto incrementó las horas de coordinación y requirió nuevos contenidos. Una muralista, quien participó en intervenciones artísticas en el centro de Santiago pintando las calles para mejorar la caminabilidad, se integró al equipo enseñándoles a niños y niñas cómo diseñar señalética e iconografía para las "Rutas Bakanes". Estas actividades hicieron atractivo el programa para aquellos niños y niñas que no gozaban de la actividad física, o no se sentían a gusto con las actividades de ciclismo, mecánica básica o movilidad en general. Cada comunidad conlleva una ecología de colaboradores que varía, pero en general el programa buscaba un equilibrio entre escolares y sus familias, profesores y otros profesionales de las mismas escuelas, entes relacionados con el transporte y departamentos municipales y regionales relacionados con la planificación (Cuadro 3).
Cuadro 2. Rutas Bakanes-Comunas Uurisdicción Municipal). Fuente: Elaboración propia, con informes comunales de la Biblioteca Nacional del Congreso (reportescomunales.bcn.cl/2017/index.php,/ Página_principal) ingresada el 11 de Diciembre del 2018. Información sobre la Partición Modal: Encuesta Origen Destino (SECTRA 2012). 


\begin{tabular}{|c|c|c|c|c|}
\hline & $\begin{array}{l}\text { Nombre } \\
\text { de Entidad } \\
\text { Colaboradora }\end{array}$ & $\begin{array}{l}\text { Descripción } \\
\text { de la Entidad }\end{array}$ & $\begin{array}{l}\text { Actividad } \\
\text { de Colaboración }\end{array}$ & Descripción de Actividades \\
\hline 1 & Redbus Urbano. & $\begin{array}{l}\text { Empresa Operadora } \\
\text { de Buses del sistema } \\
\text { de Transporte Público. }\end{array}$ & $\begin{array}{l}\text { Paseo de Cursos por las } \\
\text { instalaciones de un cen- } \\
\text { tro de flota de buses. } \\
\text { Participación en activida- } \\
\text { des programadas en cla- } \\
\text { ses. }\end{array}$ & $\begin{array}{l}\text { Trabajamos en conjunto con Redbus } \\
\text { para llevar a varios cursos hacia sus cen- } \\
\text { tros de flota para que les estudiantes } \\
\text { conocieran desde dentro cómo fun- } \\
\text { cionan este tipo operaciones. También } \\
\text { vinieron como invitados ingenieros de } \\
\text { transporte a dar su visión en nuestras } \\
\text { clases. }\end{array}$ \\
\hline 2 & $\begin{array}{l}\text { Nathalie Zamo- } \\
\text { rano. }\end{array}$ & $\begin{array}{l}\text { Socióloga de la Univer- } \\
\text { sidad de Chile. }\end{array}$ & $\begin{array}{l}\text { Participó de clases en es- } \\
\text { cuelas para enseñar téc- } \\
\text { nicas de encuesta y su uso } \\
\text { en el transporte. }\end{array}$ & $\begin{array}{l}\text { Participó de varias clases enseñando a } \\
\text { los y las estudiantes diferentes técnicas } \\
\text { que provienen de la sociología y como } \\
\text { se pueden utilizar en el mundo de la } \\
\text { movilidad. }\end{array}$ \\
\hline 3 & $\begin{array}{l}\text { Dirección de } \\
\text { Transporte Pú- } \\
\text { blico Metropoli- } \\
\text { tano (DTPM). }\end{array}$ & $\begin{array}{l}\text { Encargada de articu- } \\
\text { lar, coordinar y hacer } \\
\text { seguimiento de las ac- } \\
\text { ciones, programas y } \\
\text { medidas tendientes a } \\
\text { gestionar el transpor- } \\
\text { te público de la ciudad } \\
\text { de Santiago. }\end{array}$ & $\begin{array}{l}\text { Paseo de Cursos por las } \\
\text { instalaciones de un cen- } \\
\text { tro de flota de buses. } \\
\text { Participación en activida- } \\
\text { des programadas en cla- } \\
\text { ses. }\end{array}$ & $\begin{array}{l}\text { Trabajamos en conjunto con DTPM } \\
\text { para llevar a varios cursos hacia sus } \\
\text { instalaciones para que les estudiantes } \\
\text { observaran y tuvieran la vivencia de lo } \\
\text { que es el monitoreo del funcionamien- } \\
\text { to del sistema de transporte público. }\end{array}$ \\
\hline 4 & $\begin{array}{l}\text { Juntas de Veci- } \\
\text { nos }(7 \text { juntas de } \\
\text { Vecinos en To- } \\
\text { tal). }\end{array}$ & $\begin{array}{l}\text { Organizaciones de } \\
\text { Base, gestionadas por } \\
\text { habitantes de un mis- } \\
\text { mo sector o barrio. }\end{array}$ & $\begin{array}{l}\text { Mesas participativas. Acti- } \\
\text { vidades de Calles Abier- } \\
\text { tas. Auditorías en terreno. } \\
\text { Apoyo en actividades de } \\
\text { clases. }\end{array}$ & $\begin{array}{l}\text { Las juntas de vecinos nos ayudaron a } \\
\text { promover actividades dentro de las mu- } \\
\text { nicipalidades, realizar convocatorias, } \\
\text { apoyar con permisos e infraestructura } \\
\text { local, además de darnos una cantidad } \\
\text { infinita de información respecto a sus } \\
\text { propios barrios. }\end{array}$ \\
\hline 5 & $\begin{array}{l}\text { Organizaciones } \\
\text { Deportivas. }\end{array}$ & $\begin{array}{l}\text { Organizaciones locales } \\
\text { de barrio. }\end{array}$ & $\begin{array}{l}\text { Participación en activida- } \\
\text { des al aire libre. }\end{array}$ & $\begin{array}{l}\text { Estas organizaciones se sumaban a tra- } \\
\text { vés del préstamo de espacios de de- } \\
\text { porte (canchas, institutos para hacer } \\
\text { talleres, etc); además de apoyar en lo- } \\
\text { gísticas de seguridad para cicletadas y } \\
\text { actividades al aire libre. }\end{array}$ \\
\hline 6 & $\begin{array}{l}\text { Programas de } \\
\text { Vigilancia Co- } \\
\text { munitaria. }\end{array}$ & $\begin{array}{l}\text { Estas muchas veces es- } \\
\text { taban ligadas a juntas } \\
\text { de vecinos, pero parti- } \\
\text { cipaban diferentes ve- } \\
\text { cinos y vecinas. }\end{array}$ & $\begin{array}{l}\text { Auditorías de terreno, } \\
\text { participación de mesas y } \\
\text { mareos participativos. }\end{array}$ & $\begin{array}{l}\text { Estos programas, especialmente los de } \\
\text { la comuna El Bosque, apoyaban en dar } \\
\text { información sobre ámbitos de segu- } \\
\text { ridad en la calle y participando para } \\
\text { crear la Ruta Bakan, conectándonos } \\
\text { con negocios y socios locales por don- } \\
\text { de pasaría la ruta. }\end{array}$ \\
\hline 6 & $\begin{array}{l}\text { Organizaciones } \\
\text { Locales (De Mo- } \\
\text { vilidad Redu- } \\
\text { cida, Negocios } \\
\text { Locales, Orga- } \\
\text { nizaciones de } \\
\text { Adultos Mayo- } \\
\text { res). }\end{array}$ & $\begin{array}{l}\text { Organizaciones locales } \\
\text { que se enfocan en te- } \\
\text { máticas específicas. }\end{array}$ & $\begin{array}{l}\text { Participación en activida- } \\
\text { des al aire libre. } \\
\text { Auditorías de terreno, } \\
\text { participación de mesas y } \\
\text { mareos participativos. }\end{array}$ & $\begin{array}{l}\text { Estas organizaciones apoyaban en ac- } \\
\text { tividades al aire libre, nos llenaron de } \\
\text { sus experiencias con la movilidad di- } \\
\text { versificando nuestras miradas, y ade- } \\
\text { más sumándole prioridades, como por } \\
\text { ejemplo con grupos organizados de } \\
\text { personas en situación de discapacidad. }\end{array}$ \\
\hline
\end{tabular}

Cuadro 3. Organizaciones que participaron de Rutas Bakanes (Lautaro, Independencia, El Bosque). Fuente: Elaboración propia en base a las bitácoras mantenidas para cada escuela y la comuna como un todo, 2019. 
En el resto de esta sección resumimos las experiencias en estos tres locales, dándole un poco más de espacio a El Bosque, donde estuvimos 18 meses, para el desarrollo del programa base, y resumiendo en el caso de las otras dos ciudades.

\section{Tres colegios de El Bosque}

\begin{tabular}{|c|c|c|c|c|}
\hline & Escuelas & $\begin{array}{l}\text { N. }{ }^{\circ} \text { de } \\
\text { cursos }\end{array}$ & $\begin{array}{l}\text { N. }{ }^{\circ} \text { de } \\
\text { estudiantes }\end{array}$ & Actividades/resultados principales \\
\hline 1 & Paul Harris & $\begin{array}{l}6: \\
3 .^{\circ} \mathrm{a} \\
8 .^{\mathrm{a}}\end{array}$ & 40 & $\begin{array}{l}\text { Taller extraprogramático, los estudiantes asisten de forma volun- } \\
\text { taria y se genera un intercambio entre varios niveles que enrique- } \\
\text { ce las actividades y demanda una programación adaptada a la di- } \\
\text { versidad del grupo. }\end{array}$ \\
\hline 2 & Mario Arce Gatica & $\begin{array}{l}3: \\
3 .^{\circ} \mathrm{y} \\
5 .^{\circ}\end{array}$ & 42 & $\begin{array}{l}\text { Trabajamos con cursos completos en las asignaturas de Lenguaje y } \\
\text { Educación Física. Integramos el Currículum de Movilidad Susten- } \\
\text { table de manera transversal, logrando una relación enriquecedo- } \\
\text { ra para ambos programas y para la experiencia de los estudiantes. } \\
\text { Utilizamos la calle como fuente y lugar de aprendizaje, los estu- } \\
\text { diantes salen de la sala de clase, recorren y analizan su barrio, lo } \\
\text { que les permite hacer una resignificación de su territorio y al mis- } \\
\text { mo tiempo ubicarse como sujetos habitantes urbanos. }\end{array}$ \\
\hline 3 & Villa Santa Elena. & $\begin{array}{l}5: \\
3 .^{\circ} \mathrm{a} \\
7 .^{\circ}\end{array}$ & 20 & $\begin{array}{l}\text { Taller extraprogramático, los estudiantes asisten de forma volun- } \\
\text { taria y se genera un intercambio entre varios niveles que enrique- } \\
\text { ce las actividades y demanda una programación adaptada a la di- } \\
\text { versidad del grupo. }\end{array}$ \\
\hline
\end{tabular}

Comenzamos en dos escuelas (2016) en El Bosque (Cuadro 4), para desarrollar un programa de un año completo. A finales del 2017, habíamos completado un programa diseñado para niños y niñas de 4 a 13 años de edad, pasando por toda la educación básica, pensado de forma extra-curricular pero también complementando el curriculum formal.

El producto principal de la primera etapa fue un programa completo, organizado en módulos y ligados a asignaturas específicas relacionados con el curriculum formal educacional (Historia, Educación Física, Artes plásticas) para todas las edades hasta los 13 años; recomendaciones para calles abiertas; y actividades lúdicas de urbanismo táctico, en las calles de las escuelas y sus barrios.

Durante nuestra fase exploratoria en la comuna de El Bosque (2016) aplicamos un programa de 4 semanas en dos escuelas para explorar la conceptualización que niños y niñas tenían sobre temas como género, movilidad, obesidad, sedentarismo, sostenibilidad y equidad. En cada escuela aplicamos un taller una vez a la semana donde probamos diferentes actividades y conceptos.

Durante el 2018 surgió la oportunidad de integrar colaboradores externos a esta escuela, como por ejemplo una compañía de buses urbanos (Red Bus); Académicas de la universidad de Chile (Sociólogas); y la Dirección del Transporte Público Metropolitano (DTPM), lo cual nos permitió dirigir el programa no solo dentro de la escuela en sí, sino también en el territorio urbano en el cual se encontraba.

También en 2018, y una vez completado el programa base para prekínder hasta octavo básico con su respectiva Guía Pedagógica, comenzamos a validar el programa en otras comunas (Cuadro 2) con características distintas (Independencia, Padre Las Casas, y Lautaro), para evaluar cómo funcionaban otras realidades. Monitoreamos constante-
Cuadro 4. Resumen colegios de El Bosque. Fuente: Elaboración propia en base a las bitácoras mantenidas para cada escuela y la comuna como un todo, 20162017-2018. 
mente el programa, evaluando el nivel de compromiso de las autoridades de la escuela y de los profesores involucrados, el nivel de entusiasmo de niñas y niños y necesidades o desafíos que fueron surgiendo en el camino. Una película (LaboratorioCambioSocial, 2018) resume el desarrollo del programa e incluye retroalimentación de parte de profesores y otros miembros de la comunidad escolar.

\section{Escuela Básica Paul Harris (Comuna de El Bosque)}

Recomendada por el coordinador municipal de escuelas del gobierno local, esta escuela había desarrollado un programa integral sobre el medioambiente, certificado por el Ministerio de Educación, el cual involucraba enseñar a reciclar, manejo de residuos y cuidado del medioambiente. También los resultados del Sistema Nacional de Evaluación de Resultados de Aprendizaje en esta escuela están sobre el nivel nacional, un logro para una escuela con un índice de vulnerabilidad del $90 \%$. Por esto decidimos "co-crear", junto al personal de la escuela encargada de "formación cívica", un programa donde nos acopláramos a su "Jueves Entretenido", día de actividades distintas al programa formal del resto de la semana, a través de un programa de "Bicicletas, Género y Mecánica”.

A través de esta participación semanal, exploramos conceptos de género, relaciones de género y equidad con niños y niñas de entre 8 y 13 años de edad, mientras al mismo tiempo aprendían sobre bicicletas, movilidad y mecánica básica. De esta forma el equipo aprendía y recopilaba información sobre cómo se diferenciaban las relaciones de género entre niños y niñas, cómo se reproducían estereotipos, dándonos cuenta de que a más corta la edad de los niños y niñas más facilidad hay para reflexionar sobre ideas preconcebidas sobre el género.

Por ejemplo, les preguntamos a los niños sus opiniones sobre el hecho de que las niñas usaran las herramientas y escuchamos cosas como "no son lo suficientemente fuertes" o "es que no es una cosa de niñas". Sin embargo, cuando le preguntábamos si sus madres sabían cómo usar herramientas, todos los niños orgullosamente, decían que "por supuesto", algunos incluso decían "mi mama repara todo en nuestra casa". Ejemplos como estos son comunes y, además de revelar concepciones de género y sus relaciones entre lo masculino y lo femenino, sirven para que niños y niñas puedan visualizar sus propias contradicciones, como le pasó a este grupo de niños.

El taller de mecánica partió solo con niños, pero luego se fueron uniendo más niñas. Las niñas disfrutaron del aprendizaje y uso de las herramientas, especialmente las más jóvenes, desmantelando bicis o reparando ruedas. Incluso su participación demostró un fuerte cambio en el empoderamiento y en la confianza que tenían en su propia agencia. La mayor diferencia entre niños y niñas aparece en términos de herramientas sociales. Mientras los niños tendían a ser más individualistas, peleando por las herramientas o por cuál repuesto repararían, las niñas se apoyaban mutuamente. De hecho, los grupos compuestos solo de niñas tendían a reparar las bicis más rápidamente.

\section{Escuela Básica Mario Arce Gatica (Comuna El Bosque)}

El coordinador local de las escuelas de la municipalidad de El Bosque nos recomendó trabajar con la escuela Mario Arce Gatica ya que contaba con un equipo administrativo y docente muy dedicado y que 
contaba con una visión de aceptar a estudiantes que otros colegios no querían ingresar dentro de sus aulas. Esto hace que esta escuela se convierta en uno de los colegios con mayor índice de vulnerabilidad del país $(97 \%)$ y fue todo un desafío para nuestro equipo, pero gracias al compromiso de niños y niñas, sus profesores y la administración, incluimos el programa dentro de la educación formal en los cursos de $3 .^{\circ}, 5 .^{\circ}$ y $7 .^{\circ}$ grado de la Educación Básica.

Aquí comenzamos compartiendo historias de cómo nos movemos a través de nuestros barrios y después relacionando estas historias a un transporte sustentable y el término más integral de "movilidad". Este fue uno de los momentos más enriquecedores del programa, donde nos permitimos desarrollar juegos que dieran luz sobre el uso del espacio público y la equidad (¿Por qué un auto usa $1 / 3$ del espacio que un bus, pero lleva solo $1 / 20$ de la cantidad de personas?). También introducimos una perspectiva de inclusión al desarrollar juegos que involucraban moverse a ciegas, con carros de bebés o llevando bolsas en el transporte público. Caminamos en los barrios analizando las calles, los cruces y el espacio peatonal. Logramos un enfoque de la movilidad urbana como algo entretenida y entendible para niños y niñas de 9 a 13 años de edad.

Esta fase culminó el 2017 con un cruce peatonal diseñado y pintado con los niños y niñas en una de las esquinas de su colegio, donde habían exigido cruces peatonales a las autoridades por años por velocidades excesivas y no se habían logrado. Esto se realizó en cooperación con vecinos, la escuela, el transporte metropolitano, conductores, y por supuesto los niños y niñas. Lamentablemente, las autoridades nacionales lo denunciaron por salirse del estándar y la municipalidad terminó reemplazándolo por uno formal, años después de borrarlo.

Durante 2018 miembros del departamento Secretaría Comunal de Planificación nos invitaron a trabajar en conjunto con otros departamentos del gobierno local como Seguridad, Salud y Deporte, lo cual se plasmó en actividades de calles abiertas, sin autos, con actividades educativas y mapeos participativos, alrededor de tres escuelas que estaban participando en el programa.

De ahí pasamos de una Ruta Bakan a un Triángulo Bakan. Desde una perspectiva social, el programa se enfocó más en involucrar a vecinos y sus respectivas asociaciones y organizaciones, específicamente juntas de vecinos, organizaciones deportivas y programas de vigilancia comunitaria. También se produjo la oportunidad con el Centro de la Mujer de desarrollar una bici-escuela para mujeres, "Al Vuelo por El Bosque". Logramos un financiamiento adicional y fue implementada durante el 2018 - 2019, siendo muy bien acogida por la comunidad.

Estos desarrollos nos hicieron dejar de pensar solo en "líneas" (rutas) y comenzar a pensar en espacio, es decir, re-organizar territorios completos para hacerlos más accesibles y amigables a mujeres, niños y niñas. A un nivel práctico, sin embargo, estas tareas requerirían coordinar 10 departamentos municipales, lo cual exigía mucho de nuestro equipo, perjudicando la calidad del programa en sí.

\section{Lautaro: una ciudad entera a través de sus escuelas}

Durante 2019 el equipo se adjudicó recursos adicionales para escalar el programa en Lautaro (Cuadro 5), una ciudad pequeña del sur de Chile, experiencia que resultó muy rica en resultados y aprendizajes. Con un equipo comprometido de la Dirección de Educación de la 
municipalidad de Lautaro, implementamos el programa completo de Rutas Bakanes. Participaron seis escuelas y nueve cursos desde pre-kinder a $7 .^{\circ}$ de Básica.

Realizamos una serie de mesas participativas con organizaciones locales de personas con movilidad reducida, clubes deportivos y juntas de vecinos además de la comunidad escolar en su conjunto (profesores, administradores y asistentes de la educación), seguido por un trabajo de co-creación, a través del cual diseñamos una ruta que une las seis escuelas, un estadio deportivo, un centro de abastecimiento y lugares típicos que le aportan a la ciudad su personalidad. Estos lugares fueron reconocidos como espacios públicos relevantes principalmente por los estudiantes, niños y niñas, como lugares de aprendizaje y encuentro, y no solo de tránsito.

\begin{tabular}{|c|c|c|c|c|}
\hline & Escuelas & $\begin{array}{l}\text { N. }{ }^{o} \text { de } \\
\text { cursos }\end{array}$ & $\begin{array}{l}\text { N. }{ }^{\circ} \text { de } \\
\text { estudiantes }\end{array}$ & Actividades/resultados principales \\
\hline 1 & Guacolda & $2: 3^{\circ}$ y $7^{\circ}$ & 55 & $\begin{array}{l}\text { Excelente equipo directivo y docente, se lograron casi la to- } \\
\text { talidad de los objetivos, lo que no se pudo lograr fue debido } \\
\text { a factores sociales, como el paro de profesores y el estallido } \\
\text { social en Chile, que detuvo algunas semanas el programa } \\
\text { (para todas las escuelas del programa 2019). }\end{array}$ \\
\hline 2 & Los Carrera & $1: 7^{\circ}$ & 39 & $\begin{array}{l}\text { Trabajo más efectivo con el Programa de Integración Esco- } \\
\text { lar, por la participación de la Coordinadora en las clases. } \\
\text { Objetivos alcanzados pese a lo numeroso del grupo. }\end{array}$ \\
\hline 3 & Escuela 1 & $2: 5^{\circ}$ y $6^{\circ}$ & 60 & $\begin{array}{l}\text { Este fue el grupo con más niñas que no sabían pedalear, lle- } \\
\text { gando todas a pedalear con seguridad a mediados del pro- } \\
\text { grama. }\end{array}$ \\
\hline 4 & Escuela 6 & $1: 6^{\mathrm{o}}$ & 16 & $\begin{array}{l}\text { Taller extraprogramático de Manualidades, todas niñas, lo- } \\
\text { gramos dar un giro a las actividades y cambiar la fabricación } \\
\text { de alcancías por taller de mecánica, destrezas en bicicleta y } \\
\text { pintar un lienzo con mensajes de conciencia vial. }\end{array}$ \\
\hline 5 & Irene Frei & $1: 5^{\mathrm{o}}$ & 26 & $\begin{array}{l}\text { El entusiasmo superó dificultades de traslado y coordina- } \\
\text { ción, logrando sus objetivos en destrezas, educación vial y } \\
\text { movilidad sostenible. }\end{array}$ \\
\hline 6 & $\begin{array}{l}\text { Amelia Go- } \\
\text { doy Peña }\end{array}$ & $\begin{array}{l}\text { 2: } 6^{\circ} \text { Pre } \\
\text { Kínde r y } \\
\text { Kínder }\end{array}$ & $\begin{array}{l}16 \\
270 \text { estudiantes de kin- } \\
\text { der y Pre Kínder en } \\
\text { Jornada de Educación } \\
\text { del Tránsito. }\end{array}$ & $\begin{array}{l}\text { En este grupo, un estudiante que no participaba nunca de } \\
\text { educación física, según las profesoras, se integró a Educa- } \\
\text { ción Física, con la bicicleta, participando también en activi- } \\
\text { dades de conciencia vial y el placer de pedalear. } \\
\text { Con el Pre Kínder y Kínder realizamos el programa de psi- } \\
\text { comotricidad con bicicleta, integrado a su programa de } \\
\text { estudio y una Jornada de Educación del Tránsito en cola- } \\
\text { boración con el Programa de Psicomotricidad Muévete y } \\
\text { Aprende de la Educación Parvularia de la Municipalidad de } \\
\text { Lautaro. }\end{array}$ \\
\hline
\end{tabular}

Cuadro 5. Resumen colegios de Lautaro. Fuente: Elaboración propia en base a las bitácoras mantenidas para cada escuela y la comuna como un todo, 2019
Varias cápsulas audiovisuales (https://www.youtube.com/channel/ UCnctWSRIQGoBxXfbjyHYlAQ/videos) muestran aspectos del programa en Lautaro, que cerró su primera fase con una cicletada por la ruta diseñada. El interés de las escuelas y las autoridades locales simplificó mucho las actividades, por sobre todo, la integración de las comunidades alrededor de las escuelas, utilizando una mirada urbana basada en "calles completas" (estrategia desarrollada en Canadá y EE.UU. para restaurar espacios seguros para peatones y ciclistas a calles domi- 
nadas por automóviles). Estas requieren procesos de cambio social mayor, siendo esta experiencia una introducción a nuevas formas de mirar, vivir y diseñar la ciudad y sus sistemas de movilidad.

En Lautaro hubo planes para seguir el programa en 2020 y más allá, con fondos de la misma municipalidad y no apoyado en fondos externos como ocurrió en 2019. La nueva fase que se vislumbra para 20202022 es justamente la formación de instructores, debidamente certificados, y la creación de programas al nivel comunal, y eventualmente, regional o nacional, una nueva fase de investigación que se abrió, fruto de estos resultados.

\section{Independencia: más central pero con los desafíos de la crisis}

Si bien en Lautaro el programa logró completarse bastante cercanamente a lo planificado originalmente, en Independencia el estallido social (18 de octubre de 2019, 18-X) derivó en crisis múltiples que afectaron el trabajo en las escuelas (Cuadro 6). Independencia es una comuna donde históricamente se camina y pedalea, se puede sentir eso en los residentes más antiguos pero también en toda la población nueva, especialmente migrante, que se ha asentado en el territorio.

Por la contingencia debimos acotar el programa y decidimos darle prioridad a probar posibilidades de actividades "Rutas Bakanes en tiempos de crisis", las que se enfocaron en reuniones con los profesores y conversaciones acerca de métodos para acompañar y ayudarle a niños y niñas a procesar las emociones que estaban experimentando, por las diferentes vivencias asociadas a estos acontecimientos. Muchos barrios vivieron la represión, directa o indirectamente, al estar afectadas personas que vivían en estos lugares y, junto con una mayoría que apoyaba la agenda social levantada por estos movimientos, había gente que se restaba o que tenía mucho temor a lo que podría venir, aumentando angustias y conflictos, incluso entre vecinos y personas cercanas.

El Colegio Presidente Balmaceda estuvo tomado por los estudiantes, mientras las escuelas Luis Galdames y Nueva Zelandia casi no tuvieron alteraciones en su programa, solo cambio de horario debido a las dificultades de transporte de los docentes y trabajadores.

Estos ajustes derivaron en dos resultados principales: la decisión de la municipalidad de seguir con el programa, con financiamiento municipal, en 2020; y la decisión de parte del equipo de seguir buscando e integrando instrumentos nuevos, más relacionados con el apoyo emocional y social, para situaciones de conflicto y cambio que, todo indica, seguirán desarrollándose a lo largo de 2020 y más allá.

\begin{tabular}{|l|l|l|l|l|}
\hline Escuela & $\begin{array}{l}\text { N. }{ }^{\circ} \text { de } \\
\text { cursos }\end{array}$ & $\begin{array}{l}\text { N. }{ }^{\circ} \text { de } \\
\text { estudiantes }\end{array}$ & Resultado principal \\
\hline 1 & Luis Galdames & $1: 7 .^{\circ}$ & 43 & $\begin{array}{l}\text { Integración a la asignatura de Historia, muy buen diálogo con } \\
\text { la docente y el equipo directivo. Se logra cercanía con los estu- } \\
\text { diantes migrantes que encuentran en las clases de Rutas Baka- } \\
\text { nes un espacio afectivo donde poder expresar y procesar su mo- } \\
\text { mento de adaptación a otro país, idioma y cultura. }\end{array}$ \\
\hline 2 & Nueva Zelandia & $1: 5^{\circ}$ & 40 & $\begin{array}{l}\text { En trabajo coordinado con el docente integramos Rutas Baka- } \\
\text { nes a la asignatura de Matemáticas. Dándole un cariz práctico } \\
\text { de obtención de datos para convertir y procesar enmarcados en } \\
\text { los conceptos de Movilidad Sostenible. }\end{array}$ \\
\hline
\end{tabular}




\begin{tabular}{|l|l|l|l|l|}
\hline Escuela & $\begin{array}{l}\text { N. }{ }^{\circ} \text { de } \\
\text { cursos }\end{array}$ & $\begin{array}{l}\text { N. }{ }^{\circ} \text { de } \\
\text { estudiantes }\end{array}$ & Resultado principal \\
\hline 3 & $\begin{array}{l}\text { Presidente Bala- } \\
\text { mceda }\end{array}$ & $2: 7 .^{\circ}, 5 .^{\circ}$ & 81 & $\begin{array}{l}\text { Logramos establecer un nexo entre Rutas Bakanes y su Proyecto } \\
\text { Educativo Institucional, en sus Asignaturas de Dimensiones For- } \\
\text { mativas y Formación Ciudadana. No logramos desarrollar com- } \\
\text { pletamente la experiencia por la contingencia social, sin em- } \\
\text { bargo y en vista de la gran coincidencia, se deja para la gestión } \\
\text { 2020 la aplicación del programa completo. }\end{array}$ \\
\hline
\end{tabular}

Cuadro 6. Resumen colegios de Independencia. Fuente: Elaboración propia en base a las bitácoras mantenidas para cada escuela y la comuna como un todo, 2018-2019.
Tanto Lautaro como Independencia quedaron con el compromiso de financiar la continuidad del programa en 2020, un desafío para su continuidad, pero también una oportunidad para estudiar y evaluar caminos para este propósito. Si bien el programa en general partió con la meta de examinar, en el caso de que funcionara en las escuelas, caminos para convertirlo en una política pública, la rigidez y el centrismo extremo de una institucionalidad que aún no sale de los limitantes heredados de la constitución 1980, de la época de la junta militar, fue un primer limitante. Las olas constantes de movimientos sociales y las violaciones de los derechos humanos (post 18-X) y la probabilidad de una nueva constitución (2020-2021) aconsejan partir desde lo más local para ver si será posible seguir propagando el programa directamente desde y dentro de los espacios locales, fase nueva de investigación que partió en 2020. Durante el primer semestre de 2020, con la llegada de la pandemia de COVID-19, el equipo preparó una experiencia de Rutas Bakanes en Casa, que enfoca la calle, la movilidad y el barrio al enseñar técnicas de arte y de pintura.

Un desafío central y una oportunidad ha sido la demanda desde los niños y niñas, las escuelas y las comunidades locales, con sus gobiernos municipales, para llevar el programa al territorio e impactar así en la transformación urbana de los barrios. Como presentamos a continuación, esto nos ha entregado lecciones importantes, particularmente la importancia de situar el programa en la intersección entre los programas locales de educación, promoción de la salud y la planificación urbana. Trabajar con comunidades a través de las escuelas demostró tener un potencial muy importante para integrar a las personas y sus agrupaciones, generando un ambiente positivo entre niñas, niños, profesores, planificadores y dirigentes/comunidades locales, como agentes de cambio, capaces de co-desarrollar herramientas urbanas relacionadas con conocimientos de género, calles para todas y todos, y seguridad, para mejorar sus barrios, comunas y ciudades completas.

\section{Resultados: Lecciones, desafíos, oportunidades}

Las evaluaciones hasta la fecha han permanecido cualitativas, a través de entrevistas con personas que participan dentro de los programas y quienes han realzado el carácter colaborativo del programa, la sensibilidad frente al medio-ambiente y la salud. Dada la complejidad del ámbito urbano no hemos podido evaluar los cambios en los hábitos diarios de niños y niñas. Los resultados se manifiestan en su mayoría en cómo niños y niñas y personas adultas ven ahora su entorno urbano y además en creer en su propia capacidad de cambiarlo, si se trabaja de manera colectiva. 


\section{Lecciones de las Escuelas}

Niños y niñas tienen fuertes opiniones. Rechazaron nuestro nombre primerizo de "Rutas Seguras" y quisieron "Rutas Bakanes". Este primer aprendizaje pasó a ser el principio de co-diseño, fundamental y una las mayores fuerzas del programa. Efectivamente, después de desarrollar la guía curricular en El Bosque (2016-2017), quedamos con metas generales y un itinerario para lograrlas, situación que paradójicamente nos ha permitido aplicarlo de forma flexible, para que cada local y ciudad saque o agregue, cambie o ajuste el énfasis, hasta llegar a un programa robusto, ajustado a sus propias necesidades y condiciones.

En las escuelas más vulnerables encontramos niños y niñas que reaccionaban violentamente a cualquier desencuentro. Esto ocurría cuando el grupo tenía que elegir un juego, una intervención urbana o cumplir alguna tarea. Especialmente en grupos de niños, pero también para algunas niñas, encontramos que su primera reacción a cualquier problema era responder con una violencia inicial, normalmente verbal, que rápidamente escalaba. Los profesores trataban de mantener el orden, pero al principio no supimos cómo responder. En realidad, el paisaje urbano alrededor de las escuelas es en sí violento, con calles deteriorados, veredas destrozadas, paraderos vandalizados y áreas verdes sin cuidado, utilizadas principalmente para el tráfico de drogas o el uso de alcohol y, a veces, escenarios de una violencia institucional de parte de la policía u otras autoridades.

En la medida de que las sesiones progresaban, sin embargo, los niños y niñas iban disfrutando, siendo ellos mismos quienes censuraban y prevenían interrupciones. Los grados de violencia varían según las escuelas, pero todas presentaban violencia, ya sea verbal, física, psicológica, de género, transfóbica u homofóbica. Estos fueron temas que trabajamos a través de conversaciones amistosas, relajadas, durante los talleres de mecánica de bicicletas, pintura de señalética y otras intervenciones urbanas.

En todas las escuelas, las conversaciones iniciales revelaron poca conciencia de la temática de género, con ideas reflejando valores tradicionales y patriarcales, que típicamente separaban a las mujeres, como cuidadoras, de los hombres, trabajadores. Los niños y niñas disfrutaron de la oportunidad de repensar estas ideas, especialmente a través de dinámicas lúdicas.

Un enfoque dual del género resultó ser necesario: con las niñas nos enfocamos en empoderamiento, pero también en potenciar sus capacidades como agentes sociales y de cambio. Con los niños nos enfocamos en reducir actitudes violentas, homofóbicas, misóginas y machistas. No pudimos interactuar directamente con niños o niñas que se declaraban no binarios, disidentes o trans, pero siempre que hablamos de estos temas, hubo un interés generalizado, ya que rara vez tienen la oportunidad de hablar de los mismos.

\section{Lecciones sobre las ciudades, lugares, comunidades}

En ciudades que están modificando sus formas de movilizarse, la planificación tiende a enfocarse en infraestructura, kilómetros de ciclovías más que educación socio-cultural. Se le presta poca atención a la creación de redes o tejidos sociales que conectan personas a un sinfín de destinaciones y programas que potencian nuevos usos de la infraestructura existente. 
Fruto de este programa, donde las comunidades locales y escolares son protagonistas de su diseño y realización, descubrimos otra diferencia importante entre Rutas Bakanes y programas convencionales de rutas "seguras". El enfoque de rutas seguras adapta a niñas y niños a un entorno poco apto y seguro para ellos, mientras Rutas Bakanes les prepara para ese entorno, pero también les enseña a criticar y cambiarlo. Así, por ejemplo, un manual desarrollado por Safe Routes Center y Children's safety Network, identifica cuatro tipos de violencias: bullying, pandillas, crímenes personales y secuestros, omitiendo violencia de género, y propone soluciones esencialmente individuales para abordarlos.

Estas soluciones, como "Caminar Juntos", usar "Mapas Seguros" o "Monitores de Tránsitos" (cfr. NCSRS-CSN, 2011, pp. 4-8), no abordan los problemas de fondo, las actitudes individuales y colectivas que en su conjunto crean valores y acciones favorables o desfavorables a la seguridad de niñas, niños y mujeres, entre otras personas. Recomiendan, por ejemplo, realizar alianzas con la policía local, lo cual en nuestras realidades puede ser una espada de doble filo por los problemas de confianza e (in)seguridad derivados del actuar de la misma policía en nuestros barrios.

Como el apartado anterior revela, problemas de automóviles, seguridad en las calles, violencia de género y otros tipos de violencias están relacionados con los espacios por los cuales viajan niños y niñas, pero también con las complejas actitudes que en su conjunto son parte integral del imaginario social que define relaciones y riesgos en cada espacio compartido.

\section{Lecciones del enfoque en derechos}

En cuanto al enfoque en derechos (Cuadro 7), si bien al principio creíamos que podría ser difícil "bajar a tierra" estos principios, en la práctica resultó ser bastante sencillo plasmarlos en elementos concretos y permanentes del programa, los que fueron testeados en cada local, con buena aceptación, siempre dentro del marco de co-diseño y aplicación flexible, mencionada anteriormente.

La guía curricular que desarrollamos en las escuelas de El Bosque nos permitió ir escogiendo, con socios locales, y estructurando un proceso que tenía una lógica práctica y efectiva para todas las personas que participaban, de la escuela, de las comunidades y de las municipalidades. También permitió que los funcionarios municipales se sintieran "dueños" del programa, pudiendo agregar elementos o delegar otros en nuestro equipo de expertos. En Lautaro en particular comenzamos un proceso de traspaso de conocimientos a profesores locales, un paso delicado, ya que a menudo los profesores no quieren más responsabilidades, al sentirse sobrecargados con las que ya tienen.

Un logro tremendamente importante en este sentido fue que el programa en Lautaro e Independencia dejó de ser extracurricular y pasó a ser parte integral de las asignaturas habituales de cada nivel de educación. Así, para los profesores fue mucho más fácil integrarlo en sus propias clases, disfrutando incluso de actividades que les exigían menos responsabilidad en la generación de material y la enseñanza de habilidades. 


\begin{tabular}{|c|c|c|}
\hline Atributos del Enfoque de Derechos & $\begin{array}{l}\text { Coincidencia con las buenas prácti- } \\
\text { cas propias del enfoque basado en } \\
\text { los derechos humanos }\end{array}$ & $\begin{array}{l}\text { Elemento pertinente de Rutas Baka- } \\
\text { nes }\end{array}$ \\
\hline $\begin{array}{l}\text { Cuando se formulen las políticas y } \\
\text { los programas de desarrollo, el obje- } \\
\text { tivo principal deberá ser el ejercicio } \\
\text { pleno de los derechos humanos. }\end{array}$ & $\begin{array}{l}\text { Los programas se dirigen con prefe- } \\
\text { rencia a grupos de la población más } \\
\text { vulnerable. } \\
\text { Tanto los resultados como los proce- } \\
\text { sos son supervisados y evaluados. }\end{array}$ & $\begin{array}{l}\text { Selección de diversas escuelas que } \\
\text { comparten estas características } \\
\text { Currículum Transversal } \\
\text { Ruta Bakán }\end{array}$ \\
\hline $\begin{array}{l}\text { Un enfoque basado en los derechos } \\
\text { humanos identifica a los ciudadanos } \\
\text { y ciudadanas como titulares de estos, } \\
\text { el contenido de los derechos, y los } \\
\text { correspondientes titulares de debe- } \\
\text { res y las obligaciones (Estado), pro- } \\
\text { curando fortalecer las capacidades } \\
\text { de los primeros para demandar su } \\
\text { vigencia, y de los segundos, para rea- } \\
\text { lizarlos o crear condiciones para su } \\
\text { vigencia. }\end{array}$ & $\begin{array}{l}\text { Las personas son consideradas agen- } \\
\text { tes principales de su propio desarro- } \\
\text { llo, en lugar de receptores pasivos de } \\
\text { productos y servicios. } \\
\text { La participación es a la vez un medio } \\
\text { y un objetivo. } \\
\text { Los programas tienen como objetivo } \\
\text { reducir las desigualdades y empode- } \\
\text { rar a quienes han quedado atrás. } \\
\text { El análisis de situación se utiliza para } \\
\text { identificar las causas inmediatas, sub- } \\
\text { yacentes y fundamentales de los pro- } \\
\text { blemas de desarrollo. }\end{array}$ & $\begin{array}{l}\text { Mesas participativas } \\
\text { Intervenciones urbanas y calles abier- } \\
\text { tas en el marco de un "urbanismo } \\
\text { ciudadano" con técnicas desarrolla- } \\
\text { das por otros equipos del Lab. } \\
\text { Muy importante el apoyo de expertos } \\
\text { en urbanismo, ingeniería de trans- } \\
\text { porte y temas relacionados. }\end{array}$ \\
\hline $\begin{array}{l}\text { Los principios y las normas conteni- } \\
\text { dos en los tratados internacionales } \\
\text { de derechos humanos deben orien- } \\
\text { tar toda la labor de cooperación y } \\
\text { programación del desarrollo en to- } \\
\text { dos los sectores y en todas las fases } \\
\text { del proceso de programación. }\end{array}$ & $\begin{array}{l}\text { El proceso de desarrollo es de titula- } \\
\text { ridad local. } \\
\text { El análisis incluye a todos los grupos } \\
\text { de interés, entre ellos, las capacida- } \\
\text { des del Estado como principal ga- } \\
\text { rante de derechos y el papel de otros } \\
\text { agentes no estatales. } \\
\text { Se promueve el desarrollo y el man- } \\
\text { tenimiento de alianzas estratégicas. }\end{array}$ & $\begin{array}{l}\text { Mesas participativas } \\
\text { Ruta Bakán } \\
\text { Continuidad del programa como } \\
\text { algo propio, municipal (nueva fase } \\
\text { de testeo 2020). }\end{array}$ \\
\hline
\end{tabular}

\section{Reflexiones finales: más que seguridad, en Chile debe ser central la equidad y la agencia humana}

En Chile, durante más de 50 años, las estrategias de diseño y planificación urbana han sido dominadas por las habilidades y conocimientos de ingenieros y arquitectos. Contrastó esta adaptación chilena de las Rutas Seguras a Las Escuelas al enfocarse principalmente en las personas y sus necesidades. Involucró a niñas y niños, rompiendo algunas barreras de género, tanto en las actitudes como en las habilidades prácticas. Mejoró las capacidades de diálogo y colaboración de los estudiantes que participaron, especialmente los niños, quienes se vieron en desventaja con las niñas en tareas de mecánica y de organización de actividades.

En la medida que avanzó el programa, generó demanda para intervenir en los territorios alrededor de los colegios. Especialmente en Lautaro esto estimuló un entusiasmo por mejorar la caminabilidad y la cicloinclusión de actores importantes de la comunidad, ambición que tuvimos que moderar para poder completar las metas del proyecto como tal.

Estas experiencias demostraron la existencia de múltiples oportunidades para una gobernanza más colaborativa y más democrática, de parte de las autoridades locales, las escuelas y las comunidades colindantes. Sugieren que programas de esta naturaleza podrían simplificar las transformaciones sociales necesarias para transicionar hacia hábitos
Cuadro 7. Aplicación del enfoque de derechos en el Programa Rutas Bakanes. Columna 1: Atributos del enfoque de derechos (Oficina del Alto comisionado de las Naciones Unidas para los Derechos Humanos, 2006), Columna 2: Elementos de las buenas practicas propios del enfoque basado en derechos (PA-CIPD, 1994). 
personales, valores y ciudades que fomentan una convivencia más sustentable. La planificación, el diseño y la participación ciudadana resultaron centrales para mover estos mecanismos favorables a la creación de ciudades más saludables, más activas y más felices.

Esta metodología "bakan", que une un programa riguroso de gran calidad con la flexibilidad para adaptarse plenamente a la realidad local, demostró ser una forma efectiva de enseñar-practicar los conocimientos aprendidos durante décadas de investigación sobre transporte, salud, medio-ambiente y cambios sociales.

El programa Rutas Bakanes indica que es importante, incluso central para transiciones hacia una vida más sustentable, desarrollar capacidad cívica entre jóvenes y personas adultas. Esto se logró gracias a una cooperación activa entre personas y entidades claves: gobiernos municipales y planificadores, escuelas, organizaciones comunitarias y niños y niñas. Al final del 2018 revisamos nuestras políticas de colaboración y decidimos exigir un compromiso mayor por parte de nuestros colaboradores, especialmente aquellos gubernamentales. En 2019 nos enfocamos en desarrollar el urbanismo como parte integral de Rutas Bakanes, utilizando métodos de urbanismo ciudadano desarrollados por otras líneas de investigación de nuestro Lab (Sagaris, 2018). Quedó de manifiesto la fuerza enorme de integrar a niños y niñas como protagonistas para re-planificar sus barrios.

Cuando los programas Rutas Seguras se enfrentan a la resistencia entre padres y madres para desarrollar los programas, es común comenzar a trabajar con estos mismos padres y madres. En nuestro caso, la participación de apoderados y apoderadas puede ser muy limitada por una sobrecarga laboral, organizacional u emocional. Al principio nos encontramos con este problema incluso entre los profesores y profesoras que participaron del programa y por eso lo adaptamos.

La lección más importante de nuestro trabajo hasta ahora es que solamente adaptar a niños y niñas a un ambiente hostil no es suficiente. Tienen que saber cómo interactuar con ese ambiente y mejorarlo. Al terminar nuestro cuarto año de investigación-acción hemos visto que, aparte de entender conceptos como "transporte sostenible", "justicia en el transporte" y "equidad de género", aprender a ejercitar sus derechos como ciudadanos y ciudadanas puede ser la lección más importante que le demos a nuestros estudiantes, sus comunidades y sus escuelas. Esto parece un requisito vital para que se puedan mover libremente a través de sus barrios en condiciones de seguridad, dignidad y felicidad, que además liberen a sus cuidadores para que se enfoquen en otras tareas en vez de estar cuidándoles. 


\section{Referencias bibliográficas}

Aguilar-Farias, Nicolás; y Cortinez-O’Ryan, Andrea (2018). Nuevas políticas públicas para la promoción de la actividad física. En Mardones, Francisco; Arnaiz, Pilar; Barja, Salesa; y Rosso, Pedro (Eds.), Obesidad en Chile: ¿Qué podemos hacer? (pp. 21-36). Santiago, Chile: Ediciones UC.

Aguilar-Farias, Nicolás; Martino-Fuentealba, Pía; Carcamo-Oyarzun, Jaime; Cortinez-O’Ryan, Andrea ; Cristi-Montero, Carlos; Von Oetinger, Astrid; y Sadarangani, Kabir (2018). A regional vision of physical activity, sedentary behaviour and physical education in adolescents from Latin America and the Caribbean: results from 26 countries. International Journal of Epidemiology, 47(3), 967-986. DOI:10.1093/ije/dyy033.

Allen, Heather; Pereyra, Leda; Sagaris, Lake y Cárdenas, Galo (2019). Ella se mueve segura, Un estudio sobre la seguridad personal de las mujeres y el transporte público en tres ciudades de América Latina. Recuperado el 8 de julio de 2020 de: https:/ / scioteca.caf.com/ handle/123456789/1405.

Almandoz, Arturo (2013). Modernización urbana en América Latina. De las grandes aldeas a las metrópolis masificadas. Santiago, Chile: Colección Estudios Urbanos UC.

Alza Barco, Carlos (2014). El enfoque basado en derechos ¿Qué es y cómo se aplica a las políticas públicas?. En Burgorgue-Larsen, Laurence, Maués, Antonio y Sánchez Mojica, Beatriz Eugenia (Eds.), Derechos Humanos y Políticas Públicas. Manual (pp. 51-78). Barcelona: Red de Derechos Humanos y Educación Superior.

Argyris, Chris y Schön, Donald A. (1974). Theory in practice Increasing professional effectiveness. San Francisco: John Wiley \& Sons.

Beckmann, Jörg (2001). Automobility-A Social Problem and Theoretical Concept. Environment and Planning D: Society and Space, 19(5), 593-607. DOI: $10.1068 / \mathrm{d} 222 \mathrm{t}$

Boniface, Sadie; Scantlebury; Rachel; Watkins, Stephen J.; y Mindell, Jennifer (2015). Health implications of transport: Evidence of effects of transport on social interactions. Journal of Transport Health. 2(3), 441-446. DOI: 10.1016/j.jth.2015.05.005.

Cavill, Nick (2003). The potential of non-motorised transport for promoting health. En Tolley, Rodney (Ed.), Sustainable transport: Planning for walking and cycling in urban environments. Cambridge: Woodhead Publishing Limited.

Col-ectiu Punt 6 (2019). Urbanismo Feminista. Barcelona: Virus Editorial.

Díaz, Rodrigo y Rojas, Francisca (2017). Mujeres y Ciclismo Urbano, promoviendo políticas inclusivas de movi- lidad en América Latina. New York: Banco Inter-Americano de Desarrollo. Recuperado el 8 de julio de 2020 de: https:/ / publications.iadb.org/es/mujeresy-ciclismo-urbano-promoviendo-politicas-inclusivasde-movilidad-en-america-latina.

Elvik, Rune; y Bjørnskau, Torkel (2017). Safety-innumbers: A systematic review and meta-analysis of evidence. Safety Science, 92, 274-282. DOI: 10.1016/j. ssci.2015.07.017.

Fainstein, Susan S. (2010). The Just City. Ithaca, New York: Cornell University Press.

Faludi, Andreas (1978). Essays on planning theory and education. Oxford - New York: Pergamon Press.

Freire, Paulo (1998). Pedagogía de la Autonomía. Lanham: Rowman \& Littlefield Publishers.

Friedman, Victor J. (2008). Action Science: Creating communities of Inquiry in Communities of Practice. En Reason, Peter y Bradbury, H. (Eds.), Handbook of action research (pp. 131-143). London: SAGE.

Friedmann, John (2011). Insurgencies: essays in planning theory. New York: Routledge.

Garrard, Jan (2003). Healthy revolutions: promoting cycling among women. Health Promotion, 14(3), 213215. DOI: 10.1071/HE03213.

Gehl, Jan (2011). Life between buildings: using public spa$c e$. Washington, DC: Island Press.

Hillman, Mayer; Adams, John; y Whitelegg, John (1990). One false move... a study of children's independent mobility. London: Policy Studies Institute.

Jacobsen, Peter L. (2003). Safety in numbers: more walkers and cyclists, safer walking and bicycling. Injury Prevention, 9, 205-209. DOI: 10.1136/ip.9.3.205.

Jacobsen, Peter L.; Ragland, David R.; y Komanoff, Charles (2015). Safety in Numbers for walkers and bicyclists: exploring the mechanisms. Injury Prevention, 21, 217-220. DOI: 10.1136/injuryprev-2015-041635.

Mardones, Francisco; Arnaiz, Pilar; Barja, Salesa; y Rosso, P. (2018). Epidemia de la obesidad en el mundo y en Chile. En Mardones, Francisco; Arnaiz, Pilar; Barja, Salesa; y Rosso, Pedro (eds.), Obesidad en Chile: ¿Qué podemos hacer? (pp. 21-36). Santiago, Chile: Ediciones UC.

Margozzini, Paula; y Bambs, Claudia (2018). Obesidad: un problema de salud colectiva que requiere soluciones colectivas. En Mardones, Francisco; Arnaiz, Pilar; Barja, Salesa; y Rosso, Pedro (eds.), Obesidad en Chile: ¿Qué podemos hacer? (pp. 21-36). Santiago, Chile: Ediciones UC.

Mindell, Jennifer (2017). Transport, Health, and Inequalities. Presentation, seminar on transport and health, PUC/Regional Government, Santiago, Chile. Recuperado el 8 de julio de 2020 de: http:// 
www.cambiarnos.cl/doc-de-trabajo-seminario-redescomunitarias-y-transpote/.

Mindell, Jennifer (2018). Every breath we take, every move we make (Editorial). Journal of Transport $\mathcal{E}^{\circ}$ Health, 10, 1-2. DOI: 10.1016/j.jth.2018.08.005.

Mindell, Jennifer; Watkins, Stephen y Cohen, Judith (Eds.) (2011). Health on the Move 2. Policies for Health Promoting Transport. Stockport, Transport and Health Study Group.

NCSRS-CSN (2011). Personal Security and Safe Routes to School. Washington, DC, National Center for Safe Routes to School, Children's Safety Network. Recuperado el 8 de julio de 2020 de: http:/ / www.pedbikeinfo.org/pdf/SRTSlocal_PersonalSecurity.pdf.

Oficina del Alto Comisionado de las Naciones Unidas para los Derechos Humanos (2006). Preguntas frecuentes sobre el enfoque de Derechos Humanos. Nueva York y Ginebra: ONU. Recuperado el 8 de julio de 2020 de: https://www.ohchr.org/Documents/Publications/FAQsp.pdf.

Organización de las Naciones Unidas (1994). Programa de Acción de la Conferencia Internacional sobre la Población y el Desarrollo. El Cairo.

Organización de las Naciones Unidas (2015). Objetivos de Desarrollo Sustentable. Recuperado el 30 de septiembre de 2019 de: http:/ / www.undp.org/content/undp/es/home/sustainable-developmentgoals.html.

Páez Orellana, Katherine. Conferencia Internacional sobre la Población y el Desarrollo CIPD. Avances en América Latina (2009-2011) Katherine Páez Orellana. Recuperado el 8 de julio de: https:/ / repositorio.cepal.org/bitstream/handle/11362/7141/1/ S1200566_es.pdf.

Pucher, John; y Buehler, Ralph (2008). Making cycling irresistible: lessons from the Netherlands, Denmark and Germany. Transport Reviews, 28(4), 495-528. DOI: $10.1080 / 01441640701806612$.

Reason, Peter; y Bradbury, Hilary (eds.) (2006). Handbook of Action Research, concise paperback edition. London- New Delhi: Sage Publications.

Replogle, Michael (1992). Bicycles and cycle-rickshaws in Asian cities: issues and strategies. Transportation Research Record, 1372, 76-84.

Rojas-Rueda, David; de Nazelle, Audrey; Tainio, Marko; y Nieuwenhuijsen, Mark J. (2011). The health risks and benefits of cycling in urban environments compared with car use: health impact assessment study. British Medical Journal, 343, d4521. DOI: $10.1136 /$ bmj.d4521.

Root, Amanda (2003). Delivering sustainable transport: a social science perspective. Amsterdam-New York: Pergamon.

Rydin, Yvonne (2012). Viewpoint: Healthy cities and planning. TPR- Town Planning Review, 83(4), xiiixviii. DOI: 10.3828/tpr.2012.24.

Rydin, Yvonne et al. (2012). Shaping cities for health: complexity and the planning of urban environ- ments in the 21st century. Lancet, 379(9831): 20792108. DOI: 10.1016/S0140-6736(12)60435-8

SafeRoutesPartnership.(2019). Safe Routes to School [Entrada de blog]. Recuperado el 9 de febrero de 2019, de: https://www.saferoutespartnership.org/ safe-routes-school.

Safe Routes US (2018). What is Safe Routes to School. Sección de la web Safe Routes Partnership. Recuperado el 9 de febrero 2019 de: https:/ / www.saferoutespartnership.org/safe-routes-school/101.

Sagaris, Lake (2018). Citizen participation for sustainable transport: Lessons for change from Santiago and Temuco, Chile. Research in Transportation Economics, 69(C), 402-410. DOI: 10.1016/j.retrec.2018.05.001.

Sagaris, Lake (2019). Otra clase de amor: Ciudad Viva y el nacimiento de un urbanismo ciudadano en Chile. Santiago de Chile: RIL Editores- CEDEUS.

Sagaris, Lake; y Arora, Anvita (2016). Evaluating how cycle-bus integration could contribute to "sustainable" transport. Research in Transportation Economics, 59, 218-227. DOI: 10.1016/j.retrec.2016.05.008.

Sagaris, Lake y Arora, Anvita (2018). Cycling for Social Justice in Democratizing Contexts: Rethinking "sustainable" mobilities. En Uteng, Tanu Priya; y Lucas, Karen (Eds.), Urban Mobilities in the Global South (pp. 248-258). London-New York: Routledge.

Sagaris, Lake; y Lanfranco, Daniel (2019). "Beyond "Safe": Chilean "Kool" Routes to School Address Social Determinants of Health." Journal of Transport Eं Health, 15. DOI: 10.1016/j.jth.2019.100665.

Sagaris, Lake; y Tiznado-Aitken, Ignacio (2020). Walking and gender equity: Insights from Santiago Chile. En Oviedo Hernández, Daniel; Villamizar Duarte, Natalia; y Ardila Pinto, Ana (Eds.), Urban Mobility and Social Equity in Latin America. Bingley, UK: Emerald Publishing Group.

Sagaris, Lake; Tiznado-Aitken, Ignacio y Steiniger, S. (2017). Exploring the social and spatial potential of an intermodal approach to transport planning. International Journal of Sustainable Transportation, 11(10), 721-736.

Sánchez de Madariaga, Inés y Zucchini, Elena (2019). Measuring Mobilities of Care, a Challenge for Transport Agendas. In Lindkvist Scholten, Christina y Joelsson, Tanja (Eds.), Integrating Gender into Transport Planning: from one to many tracks (pp. 145173). Switzerland: Palgrave Macmillan.

Sandercock, Leonie (1998). Making the invisible visible: a multicultural planning history. Berkeley: University of California Press.

Shanbaug, Amit (2012, 2 de mayo). 'Rickshaw Bank' concept changes lives of thousands of pullers. The Economic Times. Recuperado el 8 de julio de 2020 de: https:/ / economictimes.indiatimes.com/industry/banking/finance/banking/rickshaw-bank-concept-changes-lives-of-thousands-of-pullers/articleshow/12967347.cms?from=mdr. 
Sheller, Mimi y Urry, John (2000). The City and The Car. International Journal of Urban and Regional Research, 24(4), 737-757. DOI: 10.1111/14682427.00276.

Tolley, Rodney (Ed.) (2003), Sustainable transport: Planning for walking and cycling in urban environments. Cambridge: Woodhead Publishing Limited.

Tainio, Marco; de Nazelle, Audrey J.; Gotschi, Thomas; Kahlmeier, Sonja; Rojas-Rueda, David; Nieuwenhuijsen, Mark J.; de Sa, Thiago Héric; Kelly, Paul; y Woodcock, James (2016). Can air pollution negate the health benefits of cycling and walking? Prev Med, 87, 233-236. DOI: 10.1016/j.ypmbed.2016.02.002.

Teschke, Kay; Reynolds, Conor, CO; Ries, Francis J.; Gouge, Brian y Winters, Meghan (2012). Bicycling:
Health Risk or Benefit? UBC Medical Journal, 3(2), 6-11.

UNEP/FIA (2016). Global Outlook on Walking and Cycling. Policies $\mathcal{E}$ realities from around the world. United Nations Environmental Program, FIA Foundation. Recuperado el 8 de julio 2020 de: https://wedocs.unep.org/bitstream/handle/20.500.11822/17030/globalOutlookOnWalkingAndCycling.pdf.

UNHabitat (2016). New Urban Agenda. Recuperado el 28 de enero de 2019 de: http:/ / habitat3.org/thenew-urban-agenda.

Urry, John (2004). The System of Automobility. Theory, Culture Society, 21(4-5), 25-39. DOI: $10.1177 / 0263276404046059$.

Sagaris, Lake; Flores, Maya; y Lanfranco, DDaniel (2020). De Rutas Seguras a Rutas Bakanes en Chile: Co-creación con enfoque de género, educación cívica y derechos. Hábitat y Sociedad, 13, 169-191.

<http://dx.doi.org/10.12795/HabitatySociedad.2020.i13.10>

\section{$\bigcirc$}




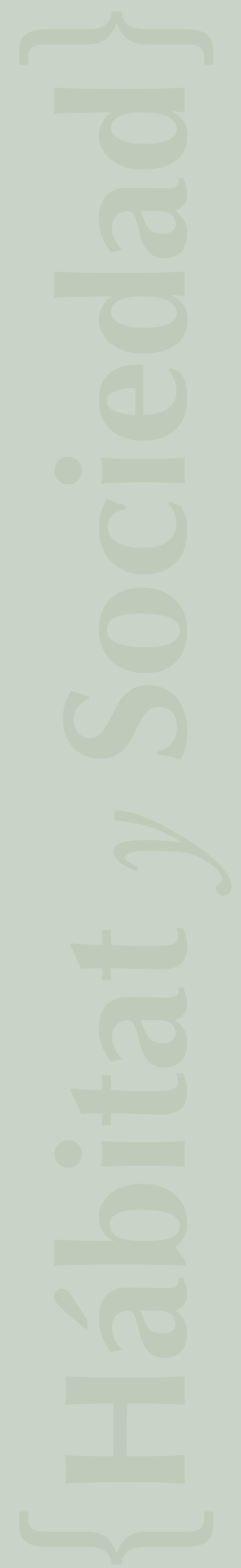

